\title{
Structural basis for bitter taste receptor activation and its potential role in targeting diabetes
}

\section{Ravinder Abrol ${ }^{1,2, *}$, Jun Tan ${ }^{2,3}$, Hongxiang Hui ${ }^{4,5}$, William A. Goddard III $^{2}$, and Stephen J. Pandol $^{1,5}$}

${ }^{1}$ Departments of Medicine and Biomedical Sciences, Cedars-Sinai Medical Center, Los Angeles, CA 90048, USA; ${ }^{2}$ Materials and Process Simulation Center, California Institute of Technology, Pasadena, CA, USA; ${ }^{3}$ Key Laboratory of Biorheological Science and Technology, Ministry of Education, Bioengineering College, Chongqing University, Chongqing, 400030, China; ${ }^{4}$ International Center for Metabolic Diseases, Southern Medical University, Guangzhou, China;

${ }^{5}$ Department of Medicine, University of California, Los Angeles, CA, USA

Corresponding author: Ravinder Abrol, Ph.D., Departments of Medicine and Biomedical Sciences, Thalians W204, Cedars-Sinai Medical Center, Los Angeles, CA 90048, USA

Submission date: September 03, 2014; Acceptance date: March 15, 2015: Publication date: March 18, 2015

\section{ABSTRACT:}

Background: Taste receptors are $\mathrm{G}$ protein-coupled receptors that, besides being present in the taste buds, have also been shown to be present in the gastrointestinal (GI) system, respiratory system, and brain, though their function at these locations is not well understood.

Objective: To understand the nutrient mediated release of gut peptides like GLP-1 from enteroendocrine L-cells of the GI system, we focused on a bitter taste receptor TAS2R38 (based on animal models) to investigate the structural basis of its potential role in the release of gut peptides.

Methods: The atomic-level structure of bitter taste receptor TAS2R38 was predicted using GEnSeMBLE, a first-principle based GPCR structure prediction method. These structures were obtained for the dominant taster haplotype (PAV) as well as for the nontaster haplotype (AVI) of the receptor. The known ligands phenylthiocarbamide (PTC) and 6-n-propylthiouracil (PTU) were docked to these structures to provide a structural basis for the taster and nontaster haplotypes.

Results: Docking of known ligands PTU and PTC to taster and nontaster haplotypes of the bitter taste receptor showed a backbone hydrogen bond to residue 262 in taster but not in nontaster haplotype, suggesting a potential mode of action of these molecules in the activation of the bitter taste receptor. 
Conclusion: These results, combined with the ability of PTC to release gut peptides from in vitro models of the enteroendocrine L-cells, suggest a potential structural basis for TAS2R38 activation that can lead to the release of those peptides. This release has a therapeutic benefit for type 2 diabetes and implies a role for bitter tasting (but safe) natural compounds targeting TAS2R38 as potential drug candidates for curing type 2 diabetes.

Key words: TAS2R38, GLP-1 release, PYY release, CCK release, enteroendocrine L cell, GPCR, protein structure prediction, GEnSeMBLE

\section{INTRODUCTION:}

Bitter, sweet, and umami taste receptors are $G$ protein-coupled lingual receptors that are also expressed in the gastrointestinal endocrine cells. They putatively sense nutrients in the ingested food and along with other nutrient receptors, like fatty acid receptors, may be responsible for modulating metabolic hormones to affect glucose homeostasis [1]. The molecular mechanisms of this modulating effect are not well understood.

On its surface, the GI tract epithelium is endowed with molecular sensing machinery that detects dietary constituents as well as gut microbial metabolites [2-5]. The sensing machinery is contained on enteroendocrine cells and neural endings interspersed between the absorptive and secretory cells of the gastrointestinal epithelium. Many types of the enteroendocrine cells have been identified, and they are mostly classified by their specific contents of endocrine transmitters. Some key examples include enteroendocrine I cells containing cholecystokinin (CCK); and L cells containing GLP-1 and PYY. The release of these agents into the blood results from interaction of sensors on the cells luminal surface to nutrient or environmental factors in the contents of the intestine. Each has specific and necessary functions on gastrointestinal tract responses including local and systemic metabolism.

GLP-1 is derived from the transcription product of the proglucagon gene. The biologically active forms of GLP-1 are GLP-1-(7-37) and GLP-1-(7-36)NH $\mathrm{NH}_{2}$ [6]. Once in the circulation, GLP-1 has a half-life of less than 2 minutes due to rapid degradation by the enzyme dipeptidyl peptidase-4 (DPP4) [7, 8]. It is a potent anti-hyperglycemic hormone, inducing glucosedependent stimulation of insulin secretion while suppressing glucagon secretion. Such glucosedependent action is particularly attractive because when the plasma glucose concentration is in the normal fasting range, GLP-1 no longer stimulates insulin to cause hypoglycemia. GLP-1 restores the glucose sensitivity of pancreatic $\beta$-cells, using a mechanism involving the increased expression of GLUT2 and glucokinase. GLP-1 also inhibits pancreatic $\beta$-cell apoptosis, stimulates the proliferation and differentiation of insulin-secreting $\beta$-cells, and inhibits gastric secretion and motility $[6,9,10]$. This delays gastric emptying, which promotes satiety and weight loss. In fact, GLP-1 analogs as well as inhibitors of endogenous GLP-1 degradation have been developed that have demonstrated efficacy for treatment of type 2 diabetes mellitus, which is the type associated with obesity $[6,10]$. Not only have the analogs been demonstrated to significantly improve insulin secretion and glucose control, they have also been found to decrease gastric emptying and increase satiety, resulting in weight loss-benefits [11]. L-cells also release two circulating forms of PYY; PYY1-36 and PYY3-36 [12, 13]. The latter form is considered the predominant one in both fasted and fed states, and is produced by the cleavage of 
the N-terminal Tyr-Pro residues from PYY1-36 by peptidase enzyme DPP4. PYY inhibits food intake via PYY-2 receptors expressed in neurons of the arcuate nucleus of the hypothalamus [14]. Other actions of PYY include slowing of gastric emptying and slowing small intestine motility.

There has been an explosion of studies using animal and human models aimed at probing the fundamental mechanistic roles of nutrient sensing receptors in the gut [1, 15-25]. These studies have identified taste receptors (sweet, umami, and bitter) as well as fatty acid receptors (activated by a broad range of chain lengths in the fatty acids) in various enteroendocrine cells. Sweet and umami taste receptors are most likely sensing or tasting [15] energy nutrients and amino acids in the food, whereas the bitter taste receptors are potentially sensing or tasting any harmful and toxic constituents in the food. Once these food components are sensed, several metabolic pathways are activated. In the case of bitter sensing components, pathways that slow down gastric emptying and food absorption are likely activated. Many of these associations are not very well characterized, especially in the context of human physiology and are being slowly uncovered. Several studies have shown that release of GLP-1 or other hormones like PYY, CCK, and ghrelin can be affected by activating one of these sensors [20, 26-33]. These associations are critical to understand the detailed role of these gustatory gut sensors in food digestion.

Physiologic roles for the peptide hormones released from the enteroendocrine cells lining the lumen of the GI tract have been known for some time, but the mechanisms underlying the "sensing" and secretion of the hormones by intestinal contents were not known. Findings are now emerging that taste receptors previously thought to be restricted to the tongue epithelium are also present in the stomach, small intestine and colon. Several enteroendocrine cell types express TAS2R-family bitter taste receptors and T1R2/3 sweet taste receptors. In fact, the enteroendocrine cells secrete GLP-1, peptide YY (PYY) or CCK in response to bitter ligands like phenylthiocarbamide (PTC), which is a specific activator of the bitter taste receptor TAS2R38 and denatonium, which activates the bitter taste receptor TAS2R47 [20, 25, 32-35].

To understand the nutrient mediated signaling of L-cells in the context of peptide hormone release, we focused on a bitter taste receptor TAS2R38 (based on animal models) to investigate its mechanistic role in the release of peptide hormones. This understanding will advance novel therapeutic avenues for targeting type 2 diabetes, specifically using bitter (but safe) components of food. In the long term, these advances are expected to show that some bitter constituents of food can be therapeutically functional.

\section{METHODS:}

The atomic-level structure prediction of the bitter taste receptor TAS2R38 required consideration of known haplotypes (taster and nontaster as described below) of the receptor. Phenylthiocarbamide (PTC) [36] and 6-n-propylthiouracil (PTU) are two potent agonists for TAS2R38. PTC is intensely bitter for some individuals but is largely tasteless for others, which has been traced to two common forms of the TAS2R38 gene, which exhibit single-nucleotide polymorphisms (SNPs) at 3 sites:

- Amino acid (AA) position 49, where either Pro or Ala is encoded,

- AA position 262, where either Ala or Val is encoded, and

- AA position 296, where either Val or Ile is encoded. 
This gives rise to two frequent haplotypes, hTAS2R38 $8_{\text {PAV }}$ and hTAS2R38 $8_{\text {AVI }}$, plus less common haplotypes hTAS2R38 $8_{\mathrm{AAI}}$, hTAS2R38 $8_{\mathrm{PVI}}$, and hTAS2R38 $8_{\mathrm{AAV}}[36,37]$, where

- hTAS2R38 Pav shows a strong response at micromolar concentrations for PTC, and

- hTAS2R38 $8_{\mathrm{AVI}}$ does not respond to PTC or PTU.

Mutational analysis [37] determined that the amino acids at position 49 and 262 have the most effect on the cellular response.

Receptor Structure Prediction: To address the molecular differences between bitter taster and nontaster populations based on the hTAS2R38 receptor and the corresponding activation mechanism by its agonists PTC and PTU, we used our computational methods $[38,39]$ to predict the atomic-level structures for a range of bitter taste receptor haplotypes: hTAS2R38 PAV (taster), hTAS2R38 $8_{\text {AVI }}$ (nontaster), hTAS2R38 $8_{\text {AAI }}$ (taster) and hTAS2R38 $8_{\mathrm{PVV}}$ (taster). The computational methods perform a complete sampling of local conformational space ( 10 trillion conformations) accessible to the seven transmembrane (TM) helices of the receptor in the lipid bilayer. The starting structure for the conformational space sampling was a homology model based on the $\beta 1$ adrenergic receptor structure [40]. The details of the structure prediction process are described in detail elsewhere [41]. The top conformations were relaxed in the lipid bilayer environment using molecular dynamics (MD) simulations (shown in Figure 1) and are discussed later.
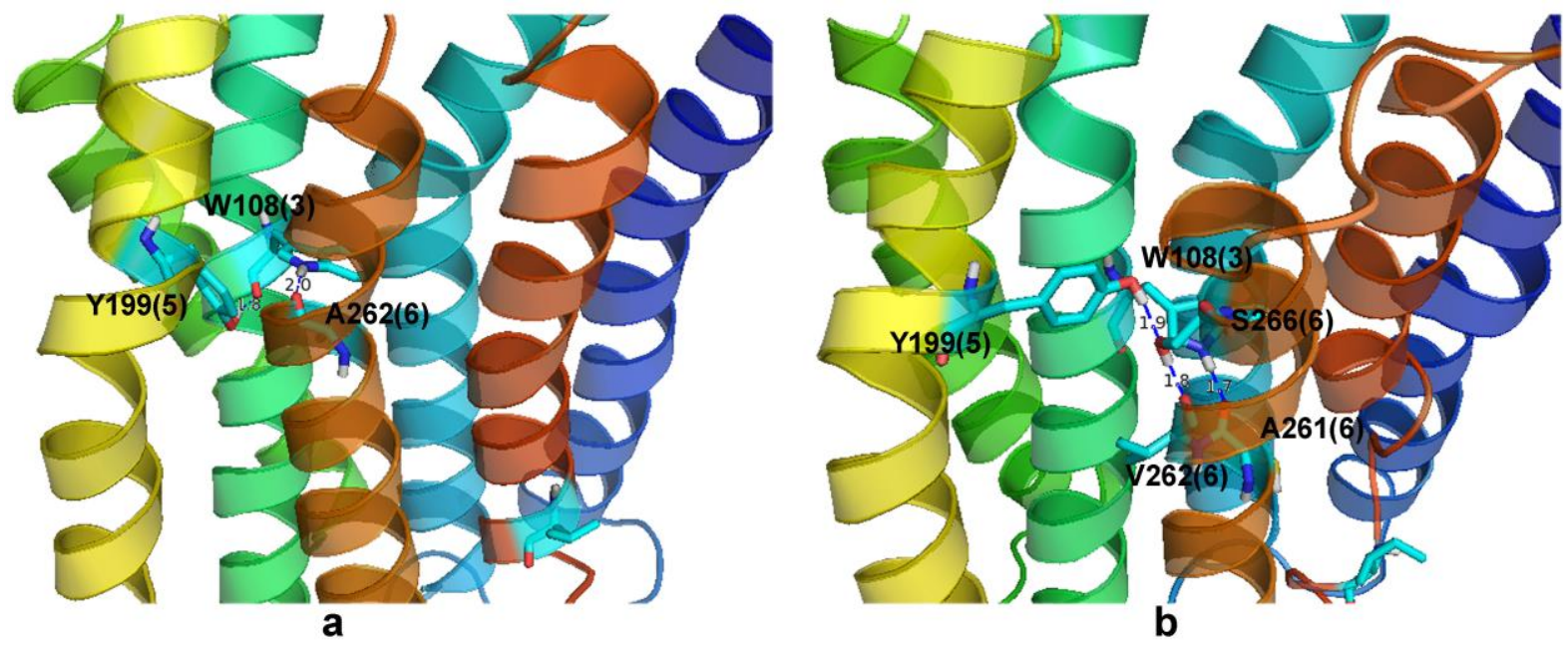

Figure 1: Predicted 3D structures of bitter taste receptors hTAS2R38 $8_{\mathrm{PAV}}$ (a) and hTAS2R $38_{\mathrm{AVI}}$ (b) after $10 \mathrm{~ns}$ of molecular dynamics (MD) simulations in the explicit lipid environment. Residues forming interhelical $\mathrm{H}$-bonds are highlighted here and they are stable during MD.

Ligand Docking: We then used GenDock methodology [42] to predict the binding sites and binding affinity for PTC and PTU to the predicted atomic structures of both taster and nontaster receptor forms [41]. This docking protocol performs an exhaustive sampling of the ligand poses (for multiple ligand conformations) in putative binding sites and clusters the ligand poses into different families for an efficient evaluation of binding energies. The method also accounts for protein flexibility by using alanines in place of bulky hydrophobic residues for ligand pose search stage, and then reintroducing those residues along with a custom optimization of the binding site for each of the top 100 ligand poses. The resulting complexes of PTC and PTU were also relaxed in the lipid environment using MD simulations (shown in Figure 2 and 
discussed below). The energetic and structural differences exhibited by the taster and nontaster receptors were analyzed to gain insight into their phenotypic taster differences.

\section{RESULTS AND DISCUSSION:}

\section{Structural analysis}

The predicted protein structures for the taster hTAS2R38 $8_{\mathrm{PAV}}$ and the nontaster hTAS2R38 $8_{\mathrm{AVI}}$ receptor forms are shown in Figure 1, relaxed in the lipid bilayer environment using molecular dynamics (MD) simulations. The taster receptor form displays two interhelical hydrogen bonds: Y199 (TM5) - W108 (TM3) and W108 (TM3) - A262 (TM6). The nontaster receptor form displays two different interhelical hydrogen bonds: W108 (TM3) - A261 (TM6) and Y199 (TM5) - A266 (TM6).
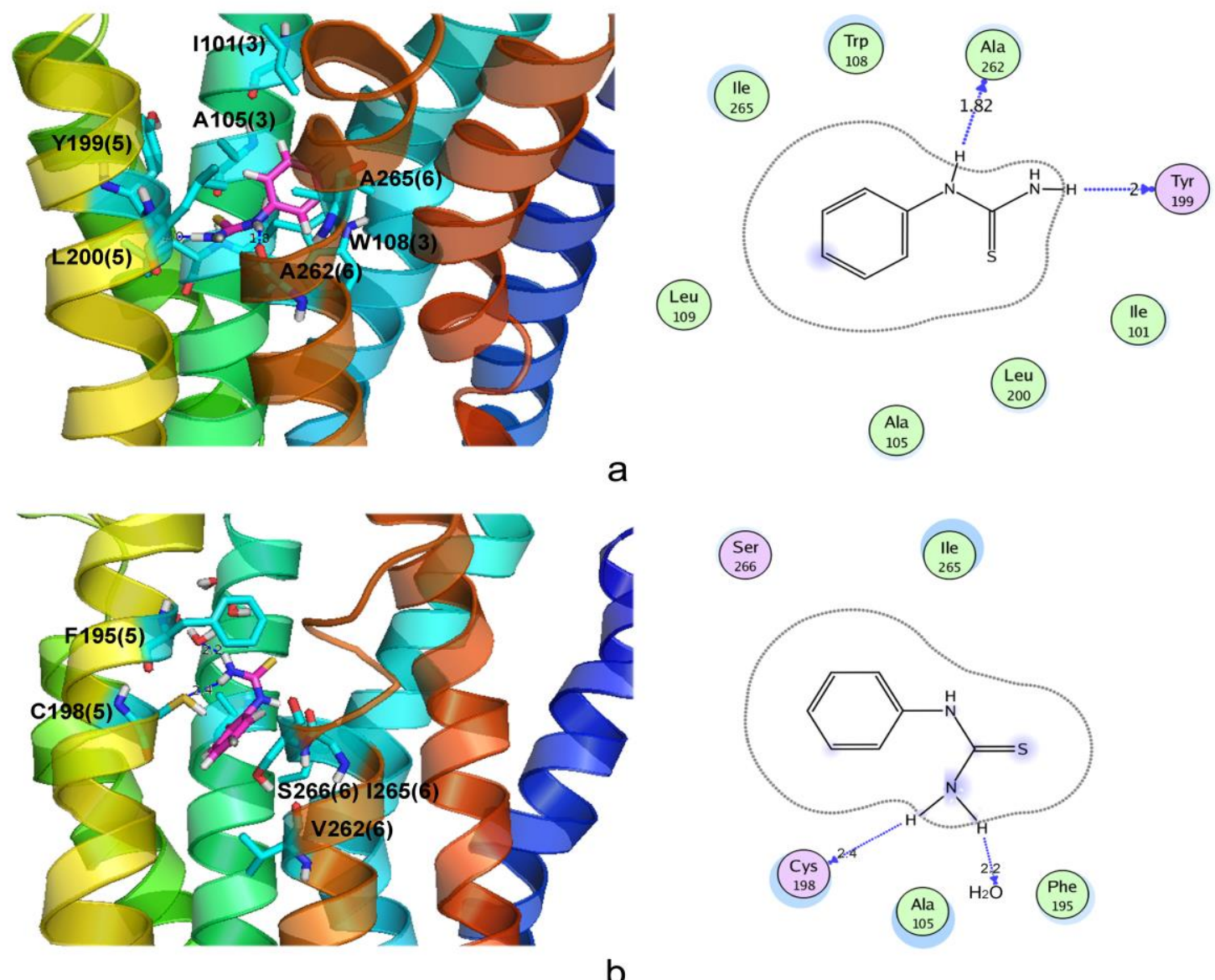

b

Figure 2: The final binding sites of PTC in hTAS2R38 ${ }_{\text {PAV }}$ (a) and hTAS2R38 $8_{\text {AVI }}$ (b) after 10 ns of MD simulations in the lipid bilayer environment. The essential elements of the binding mode are retained while additional favorable interactions are found.

The predicted ligand binding energy for PTC (and also PTU) in complex with TAS2R38 was similar in magnitude for the taster and nontaster receptor forms of TAS2R38. The phenotypic taste difference potentially arises from the difference in ligand binding modes exhibited by the molecules in the taster and nontaster receptors, and how these modes might or might not activate the taste receptor. Figure 2 shows the detailed binding site of PTC for the taster hTAS2R38 $8_{\text {PAV }}$ (Figure 2a) and the nontaster hTAS2R38 $8_{\text {AVI }}$ (Figure 2b) receptor forms, 
relaxed in the lipid environment using MD simulations. PTC forms strong interactions with both TM5 and TM6 in the taster hTAS2R38 ${ }_{\text {PAV }}$ complex (Figure 2a). The binding of ligands between TM5 and TM6 breaks the strong coupling between TM3 and TM6, and between TM3 and TM5 that was present in the apo form of the receptor. In the nontaster hTAS2R $38_{\mathrm{AVI}}$ complex, PTC breaks interhelical hydrogen bonds between W108 (TM3) and A261 (TM6) present in the apo receptor, while not those between Y199 (TM5) and A266 (TM6).

Both PTC and PTU form a stable H-bond with residue 262 of the taster (hTAS2R38 PAV) receptor form and not with that of the nontaster (hTAS2R38 $8_{\mathrm{AVI}}$ ) receptor form. So, this residue appears to be very important for PTC/TAS2R38 taster differences consistent with experiments [37].

\section{Functional and Therapeutic Implications}

It has been shown using mouse enteroendocrine STC-1 cells that TAS2R38 receptor is one of the many bitter taste receptors expressed in these cells [17]. In addition, PTC has been shown to induce robust intracellular $\left[\mathrm{Ca}^{2+}\right]$ response [18] and CCK release [18, 33] in these cells. The Go protein gustducin $\left(\mathrm{G} \alpha_{\text {gust }}\right)$ has also been found to be co-expressed with GLP-1 and PYY gut hormones [25]. This $\mathrm{G}$ protein mediates taste receptor signaling by coupling to sweet and bitter taste receptors. These data strongly suggest that activating TAS2R38 might result in the release of gut peptides like GLP-1, PYY, and CCK. However, the subcellular signaling pathways mediating gut peptide release have not been fully explored in terms of differences in hTAS2R38 PAV $_{\text {and }}$ hTAS2R38 $8_{\text {AVI }}$ haplotypes, due in part to technical challenges in handling enteroendocrine cells. In addition, as previously mentioned, several other nutrient receptors (sweet taste, fatty acid, peptide receptors) have also been found [1] in enteroendocrine cells that release the gut peptides. These data suggest a complex set of signaling cascades that can modulate the release of gut peptides and potentially cause metabolic effects. This also makes the nutrient receptors very attractive therapeutic targets for metabolic diseases with abnormal gut peptide signaling. From the context of TAS2R38 described in this study, bitter (but safe) components of food that can activate this receptor can become promising therapeutic candidates if the signaling pathways connecting such receptors and gut peptides are explored in detail. The ligand binding sites for TAS2R38 receptor presented in this study open the possibility to screen and identify novel "bitter" molecules that can activate this receptor and cause desirable metabolic effects.

Conclusion: Nutrient receptors like bitter taste receptors are promising therapeutic targets for metabolic diseases. Differences in ligand binding modes of bitter taster and nontaster TAS2R38 receptor forms suggest a potential signature for the activation of this receptor. Molecular approaches using receptor structures and activation signatures presented in this study have the potential to identify natural agonist compounds (both natural and synthetic) that can be functional in treating metabolic disorders like diabetes.

\section{REFERENCES:}

1. Janssen S, Depoortere I. Nutrient sensing in the gut: new roads to therapeutics? Trends in Endocrinology and Metabolism 2013; 24: 92-100. 
2. Breer H, Eberle J, Frick C, Haid D, Widmayer P. Gastrointestinal chemosensation: chemosensory cells in the alimentary tract. Histochem Cell Biol 2012; 138: 13-24.

3. Sclafani A, Ackroff K. Role of gut nutrient sensing in stimulating appetite and conditioning food preferences. Am J Physiol Regul Integr Comp Physiol 2012; 302: R1119-33.

4. Steinert RE, Beglinger C. Nutrient sensing in the gut: interactions between chemosensory cells, visceral afferents and the secretion of satiation peptides. Physiol Behav 2011; 105: 62-70.

5. Nguyen CA, Akiba Y, Kaunitz JD. Recent advances in gut nutrient chemosensing. Curr Med Chem 2012; 19: 28-34.

6. Donnelly D. The structure and function of the glucagon-like peptide-1 receptor and its ligands. Br J Pharmacol 2012; 166: 27-41.

7. Gorrell MD. Dipeptidyl peptidase IV and related enzymes in cell biology and liver disorders. Clin Sci (Lond) 2005; 108: 277-92.

8. Pei Z. From the bench to the bedside: dipeptidyl peptidase IV inhibitors, a new class of oral antihyperglycemic agents. Curr Opin Drug Discov Devel 2008; 11: 512-32.

9. Cho YM, Merchant CE, Kieffer TJ. Targeting the glucagon receptor family for diabetes and obesity therapy. Pharmacol Ther 2012; 135: 247-78.

10. Edwards KL, Stapleton M, Weis J, Irons BK. An update in incretin-based therapy: a focus on glucagon-like peptide-1 receptor agonists. Diabetes Technol Ther 2012; 14: 951-67.

11. Davies M, Speight J. Patient-reported outcomes in trials of incretin-based therapies in patients with type 2 diabetes mellitus. Diabetes Obes Metab 2012; 14: 882-92.

12. le Roux CW, Bloom SR. Peptide YY, appetite and food intake. Proc Nutr Soc 2005; 64: 213-6.

13. Small CJ, Bloom SR. The therapeutic potential of gut hormone peptide YY3-36 in the treatment of obesity. Expert Opin Investig Drugs 2005; 14: 647-53.

14. Ueno H, Yamaguchi H, Mizuta M, Nakazato M. The role of PYY in feeding regulation. Regul Pept 2008; 145: 12-6.

15. Sternini C, Anselmi L, Rozengurt E. Enteroendocrine cells: a site of 'taste' in gastrointestinal chemosensing. Curr Opin Endocrinol Diabetes Obes 2008; 15: 73-8.

16. Rozengurt E. Taste receptors in the gastrointestinal tract. I. Bitter taste receptors and alpha-gustducin in the mammalian gut. Am J Physiol Gastrointest Liver Physiol 2006; 291: G171-7.

17. Wu SV, Chen MC, Rozengurt E. Genomic organization, expression, and function of bitter taste receptors (T2R) in mouse and rat. Physiol Genomics 2005; 22: 139-49.

18. Wu SV, Rozengurt N, Yang M, Young SH, Sinnett-Smith J, Rozengurt E. Expression of bitter taste receptors of the T2R family in the gastrointestinal tract and enteroendocrine STC-1 cells. Proc Natl Acad Sci U S A 2002; 99: 2392-7.

19. Steinert RE, Gerspach AC, Gutmann H, Asarian L, Drewe J, Beglinger C. The functional involvement of gut-expressed sweet taste receptors in glucose-stimulated secretion of glucagon-like peptide-1 (GLP-1) and peptide YY (PYY). Clin Nutr 2011; 30: 524-32. 
20. Jang HJ, Kokrashvili Z, Theodorakis MJ, Carlson OD, Kim BJ, Zhou J, Kim HH, Xu X, Chan SL, Juhaszova M, Bernier M, Mosinger B, Margolskee RF, Egan JM. Gutexpressed gustducin and taste receptors regulate secretion of glucagon-like peptide-1. Proc Natl Acad Sci U S A 2007; 104: 15069-74.

21. Karaki S, Tazoe H, Hayashi H, Kashiwabara H, Tooyama K, Suzuki Y, Kuwahara A. Expression of the short-chain fatty acid receptor, GPR43, in the human colon. J Mol Histol 2008; 39: 135-42.

22. Karaki S, Mitsui R, Hayashi H, Kato I, Sugiya H, Iwanaga T, Furness JB, Kuwahara A. Short-chain fatty acid receptor, GPR43, is expressed by enteroendocrine cells and mucosal mast cells in rat intestine. Cell Tissue Res 2006; 324: 353-60.

23. Sykaras AG, Demenis C, Case RM, McLaughlin JT, Smith CP. Duodenal enteroendocrine I-cells contain mRNA transcripts encoding key endocannabinoid and fatty acid receptors. PLoS One 2012; 7: e42373.

24. Sternini C. Taste receptors in the gastrointestinal tract. IV. Functional implications of bitter taste receptors in gastrointestinal chemosensing. Am J Physiol Gastrointest Liver Physiol 2007; 292: G457-61.

25. Rozengurt N, Wu SV, Chen MC, Huang C, Sternini C, Rozengurt E. Colocalization of the alpha-subunit of gustducin with PYY and GLP-1 in L cells of human colon. Am J Physiol Gastrointest Liver Physiol 2006; 291: G792-802.

26. Xiong Y, Swaminath G, Cao Q, Yang L, Guo Q, Salomonis H, Lu J, Houze JB, Dransfield PJ, Wang Y, Liu JJ, Wong S, Schwandner R, Steger F, Baribault H, Liu L, Coberly S, Miao L, Zhang J, Lin DC, Schwarz M. Activation of FFA1 mediates GLP-1 secretion in mice. Evidence for allosterism at FFA1. Mol Cell Endocrinol 2013; 369: 119-29.

27. Lan H, Lin HV, Wang CF, Wright MJ, Xu S, Kang L, Juhl K, Hedrick JA, Kowalski TJ. Agonists at GPR119 mediate secretion of GLP-1 from mouse enteroendocrine cells through glucose-independent pathways. Br J Pharmacol 2012; 165: 2799-807.

28. Luo J, Swaminath G, Brown SP, Zhang J, Guo Q, Chen M, Nguyen K, Tran T, Miao L, Dransfield PJ, Vimolratana M, Houze JB, Wong S, Toteva M, Shan B, Li F, Zhuang R, Lin DC. A potent class of GPR40 full agonists engages the enteroinsular axis to promote glucose control in rodents. PLoS One 2012; 7: e46300.

29. Liou AP, Lu X, Sei Y, Zhao X, Pechhold S, Carrero RJ, Raybould HE, Wank S. The Gprotein-coupled receptor GPR40 directly mediates long-chain fatty acid-induced secretion of cholecystokinin. Gastroenterology 2011; 140: 903-12.

30. Lu X, Zhao X, Feng J, Liou AP, Anthony S, Pechhold S, Sun Y, Lu H, Wank S. Postprandial inhibition of gastric ghrelin secretion by long-chain fatty acid through GPR120 in isolated gastric ghrelin cells and mice. Am J Physiol Gastrointest Liver Physiol 2012; 303: G367-76.

31. Hao S, Sternini C, Raybould HE. Role of CCK1 and Y2 receptors in activation of hindbrain neurons induced by intragastric administration of bitter taste receptor ligands. Am J Physiol Regul Integr Comp Physiol 2008; 294: R33-8. 
32. Kokrashvili Z, Mosinger B, Margolskee RF. Taste signaling elements expressed in gut enteroendocrine cells regulate nutrient-responsive secretion of gut hormones. Am J Clin Nutr 2009; 90: 822S-825S.

33. Chen MC, Wu SV, Reeve JR, Jr., Rozengurt E. Bitter stimuli induce Ca2+ signaling and CCK release in enteroendocrine STC-1 cells: role of L-type voltage-sensitive Ca2+ channels. Am J Physiol Cell Physiol 2006; 291: C726-39.

34. Jeon TI, Zhu B, Larson JL, Osborne TF. SREBP-2 regulates gut peptide secretion through intestinal bitter taste receptor signaling in mice. J Clin Invest 2008; 118: 3693 700 .

35. Clark AA, Liggett SB, Munger SD. Extraoral bitter taste receptors as mediators of offtarget drug effects. FASEB J 2012; 26: 4827-31.

36. Kim UK, Jorgenson E, Coon H, Leppert M, Risch N, Drayna D. Positional cloning of the human quantitative trait locus underlying taste sensitivity to phenylthiocarbamide. Science 2003; 299: 1221-5.

37. Bufe B, Breslin PA, Kuhn C, Reed DR, Tharp CD, Slack JP, Kim UK, Drayna D, Meyerhof $\mathrm{W}$. The molecular basis of individual differences in phenylthiocarbamide and propylthiouracil bitterness perception. Curr Biol 2005; 15: 322-7.

38. Abrol R, Griffith AR, Bray JK, Goddard WA, 3rd. Structure prediction of G proteincoupled receptors and their ensemble of functionally important conformations. In: Vaidehi N, Klein-Seetharaman J, eds. Membrane Protein Structure: Methods and Protocols. Volume 914. 2012/09/15 ed. New York: Humana, 2012: 237-54.

39. Bray JK, Abrol R, Goddard WA, 3rd, Trzaskowski B, Scott CE. SuperBiHelix method for predicting the pleiotropic ensemble of G-protein-coupled receptor conformations. Proc Natl Acad Sci U S A 2013: In press.

40. Warne T, Serrano-Vega MJ, Baker JG, Moukhametzianov R, Edwards PC, Henderson R, Leslie AG, Tate CG, Schertler GF. Structure of a beta1-adrenergic G-proteincoupled receptor. Nature 2008; 454: 486-91.

41. Tan J, Abrol R, Trzaskowski B, Goddard WA, 3rd. 3D Structure prediction of TAS2R38 bitter receptors bound to agonists phenylthiocarbamide (PTC) and 6-npropylthiouracil (PROP). J Chem Inf Model 2012; 52: 1875-85.

42. Goddard WA, 3rd, Kim SK, Li Y, Trzaskowski B, Griffith AR, Abrol R. Predicted 3D structures for adenosine receptors bound to ligands: comparison to the crystal structure. J Struct Biol 2010; 170: 10-20. 